\title{
An assessment of the Impact of COVID-19 Related Social Distancing Measures on the Stress Levels of students
}

\author{
Luke Edward Harding Bradley ${ }^{1}$ and Luke Reaper ${ }^{1}$ \\ ${ }^{1}$ St. Stephens International School, Rome, Italy \\ ${ }^{2}$ Behaviours and Attitudes Ltd.
}

\section{ABSTRACT}

Since the novel coronavirus was first reported in China in early 2020, governments have aimed to cull its spread and raise awareness of the symptoms of the infection. These measures are collectively known as social distancing and self-isolation. Prior to COVID-19, 85\% of students in university reported feeling overwhelmed by everything they had to do at some point within the prior year (AADA, 2015). Organizations treating teen anxiety and depression are highlighting the impact of isolation on teenagers and young adults and claim an association with a decline in self-care and a greater risk of suicide (Newport Academy, 2020). Given the pre-existing high levels of stress and mental strain experienced by students, the consequences of social isolation may more significantly impact students in comparison with non-students. This study uses the State-Trait Anxiety Inventory (STAI) index to understand the impact that social distancing and self-isolation has on the mental health of students and non-students globally. 502 responses were gathered globally with most respondents residing in the United States of America, Italy and Ireland.

The results of this study suggest that the COVID-19 related Social Distancing and Self-isolation lead to a greater increase in stress among students than among adults as measured by STAI. The reported stress was highest among high school age students and among female students generally. The reported causes of this stress are primary related to the impact on education of the measures rather than directly related to the health consequences pandemic.

\section{Methods}

The State-Trait Anxiety Inventory (STAI) (Spielberger, 1968), an inventory test used to measure anxiety, was used to assign a numerical value to an individual's stress level. This test is divided into two 40-question segments: The State segment which quantifies how a situation impacts an individual's anxiety level, and the Trait segment which quantifies the degree an individual's genetics cause anxiety in an individual. For this study, only the State segment was used, in order to quantify the feelings of anxiety individuals may be feeling in social isolation.

In this test, individuals are presented with a series of statements that could be used to describe their current state, including "I feel calm" and "I am worried". The respondent is then asked to describe how accurate the statement is to their current situation, using a five-point scale ranging from "not at all" to "very much so".

In addition to this anxiety inventory, a set of demographic questions was used to establish age, occupation, education level and household size. This was collected to support analysis of the STAI scores in relation to these demographics. In order to protect the identities of the individuals answering the survey, the responses were anonymous and contained no identifying information.

The online survey was distributed on social media platforms (Instagram and Facebook) from Thursday May 7th 2020 to Thursday May 26th 2020. A total of 502 responses were received. Most respondents resided in the United States 
of America, United Kingdom, Italy and Ireland. Reflecting this region level analysis focused on comparisons between the United States of America and these three European countries.

The survey is shown in Figure 1.

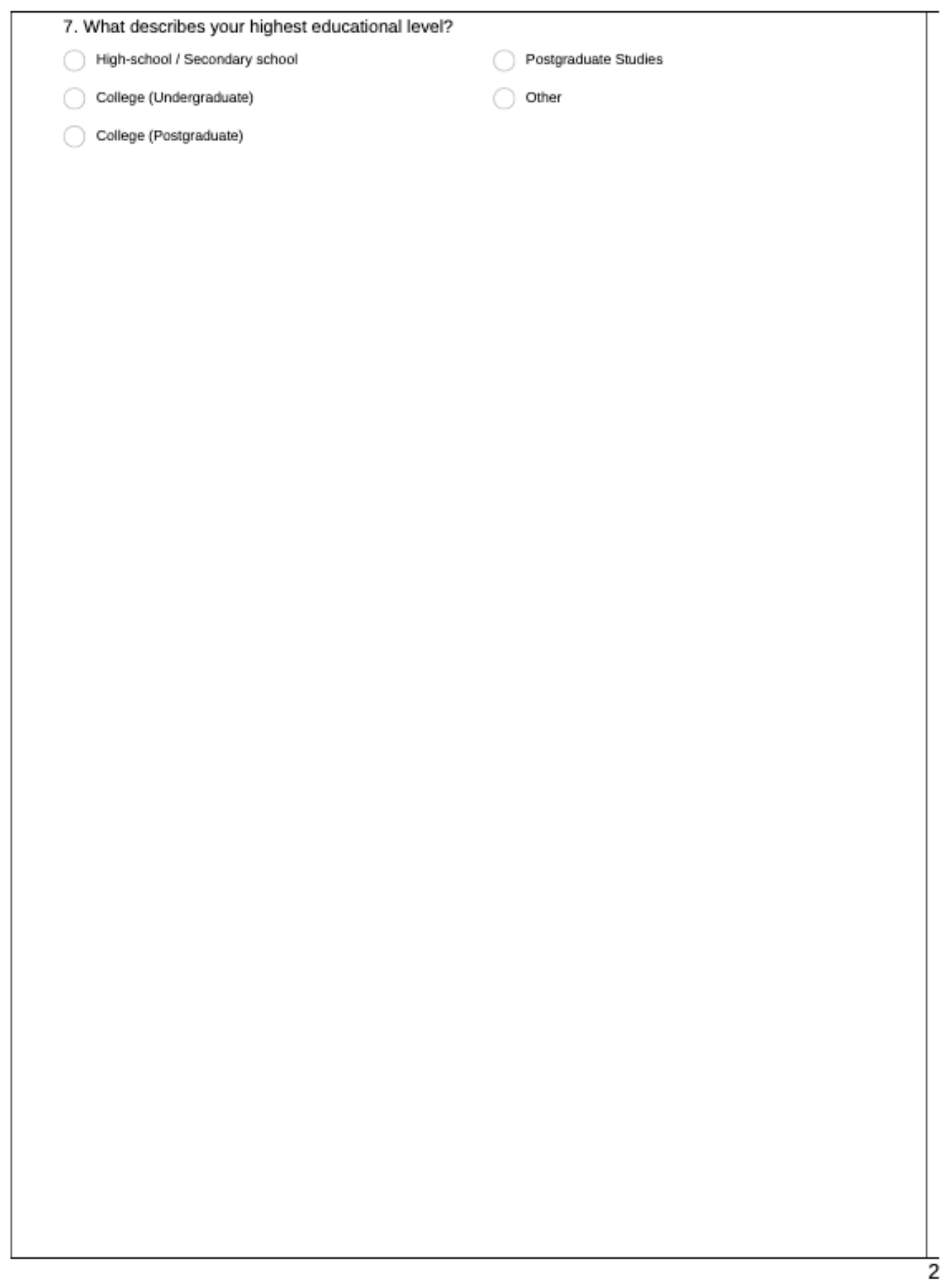

Figure 1. Survey instrument 


\section{Anxiety during Social Distancing}

8. What describes your current educational level?
High-school / Secondary school
Postgraduate Studies
College (Undergraduate)
Other
College (Postgraduate)

9. What grade / class were you in when mandatory social distancing was implemented?* *Please fill in the option for the academic system applicable to you

\begin{tabular}{|rrrr} 
& High School & Secondary School & College \\
School Year & $*$ & $*$
\end{tabular}




\section{Anxiety during Social Distancing}

- 10. A number of statements which people have used to describe themselves are given below. Read each statement and then select the option at the end of the statement that indicates how you feel right now, that is, at this moment. There is no right or wrong answers. Do not spend too much time on any one statement but give the answer which seems to describe your present feelings best.

I feel calm
I feel secure
I am tense
I feel strained
I feel at ease
I feel upset
I am presently worrying
over possible
misfortunes
I feel satisfied
I feel trightened
I feel comfortable
I feel self confident
I feel nervous
I am jittery
I feel indecisive
I am relaxed
I feel content
I am worried
I feel confused
I feel steady
I feel pleasant




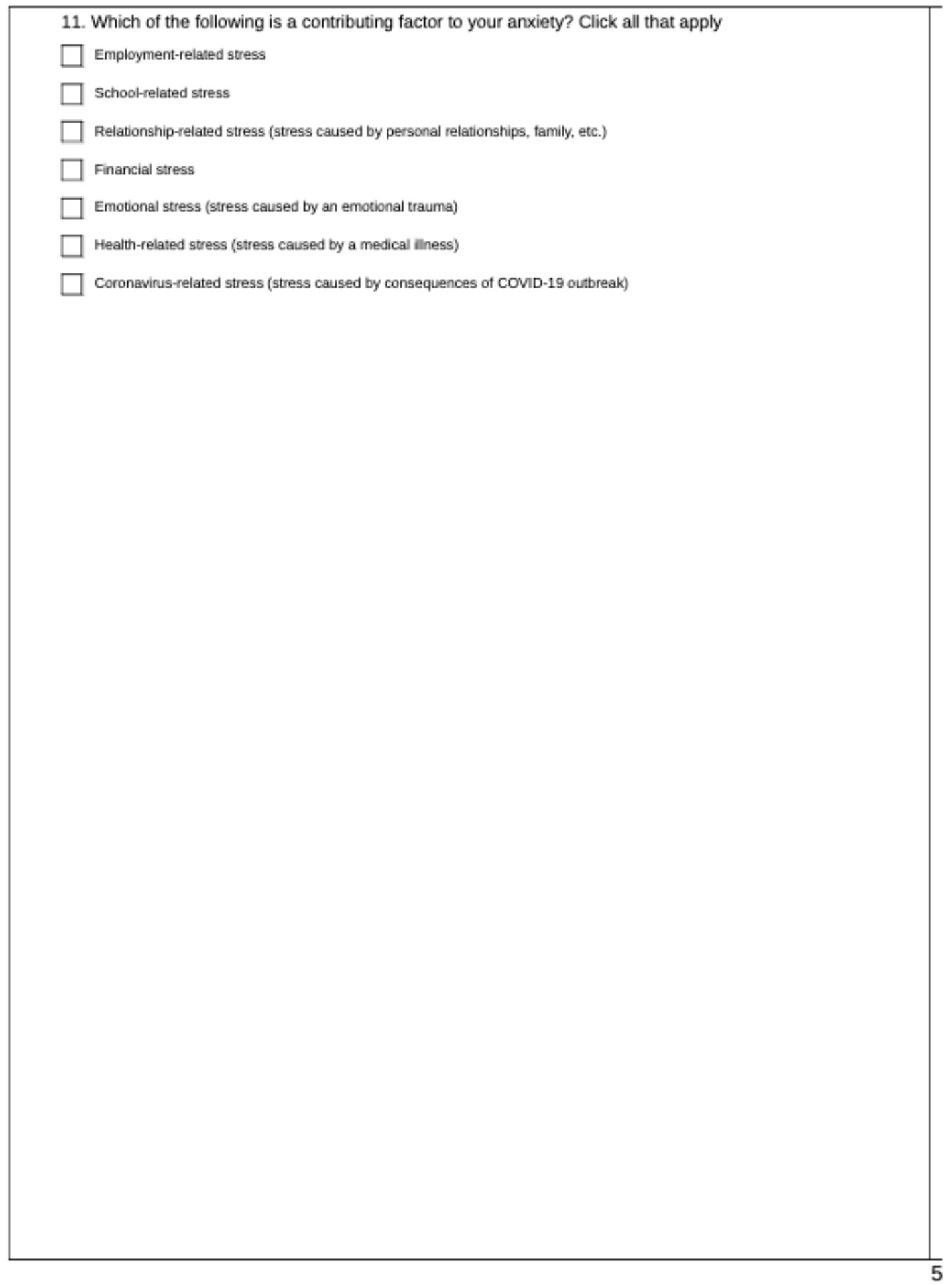




\section{Anxiety during Social Distancing}

12. Which of the following best describes the source of your educational stress?

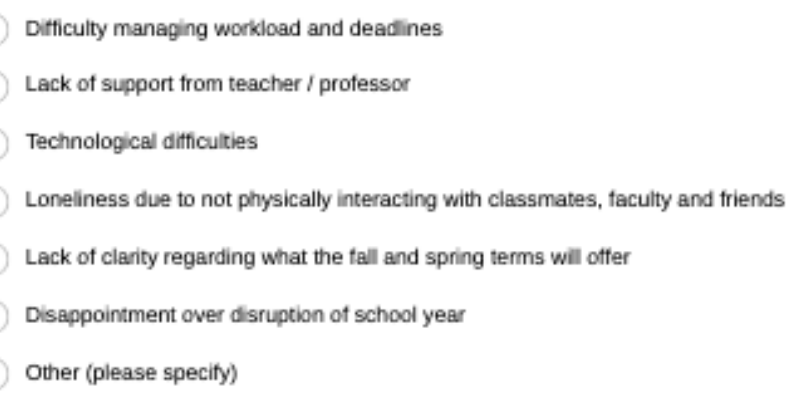




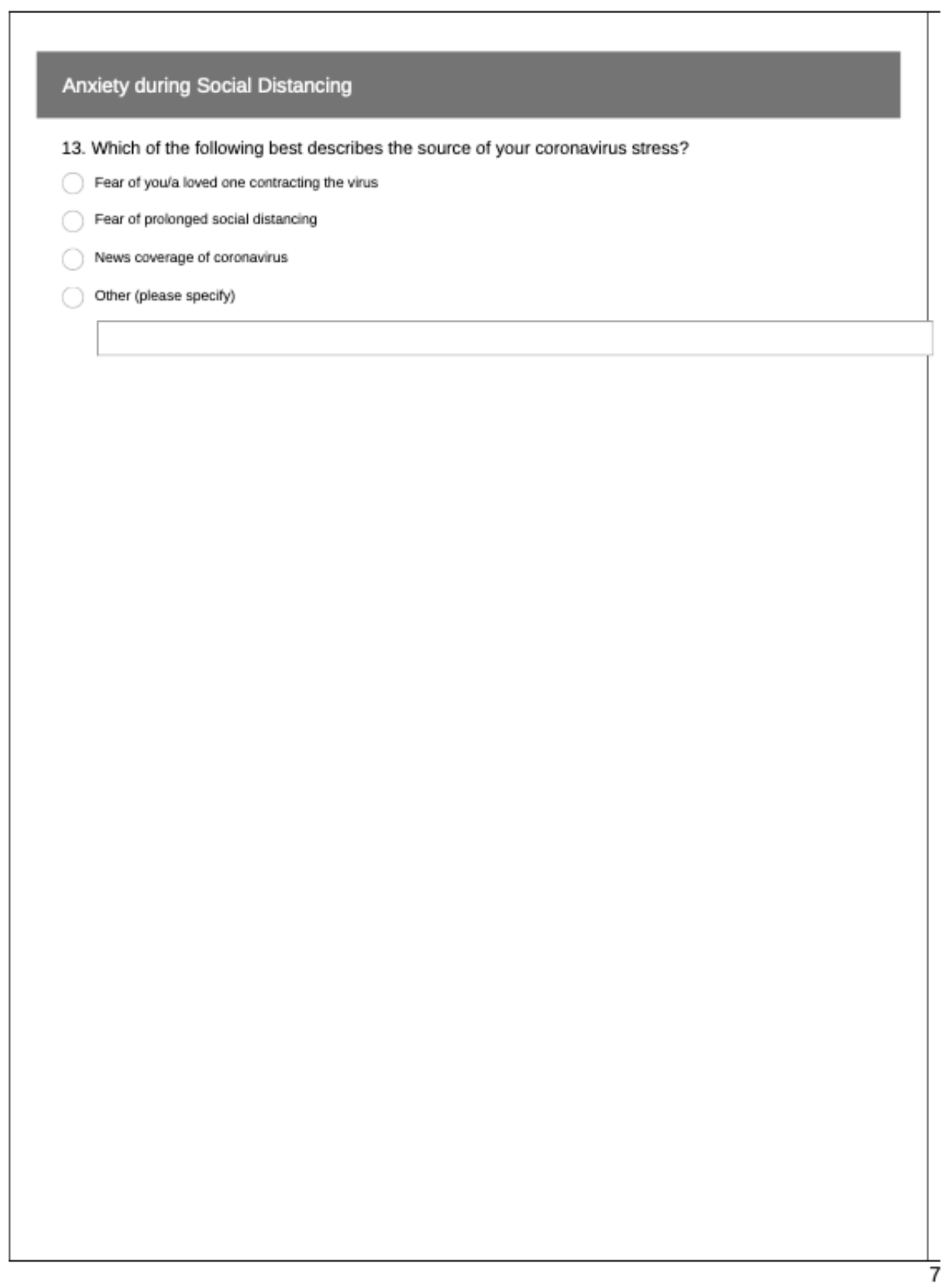




\section{Results}

\section{Profile of the sample}

Of the 502 respondents, 367 (73\%) were female, 130 (26\%) were male and 2 reported as "other". Due to the small sample size of those who reported as "other", their average STAI index may not be an accurate representation. When asked about their occupation, 286 individuals listed their occupation as "Student".

Reflecting the focus of the study on young people and the survey targeting, the largest number of respondents within the sample size were under 18s (157) and the sample size of those aged 18-24 was 167.

There were 142 employed adults which were used as the comparison set because they also experienced significant changes in daily routine due to COVID-19.

\section{Analysis of index components}

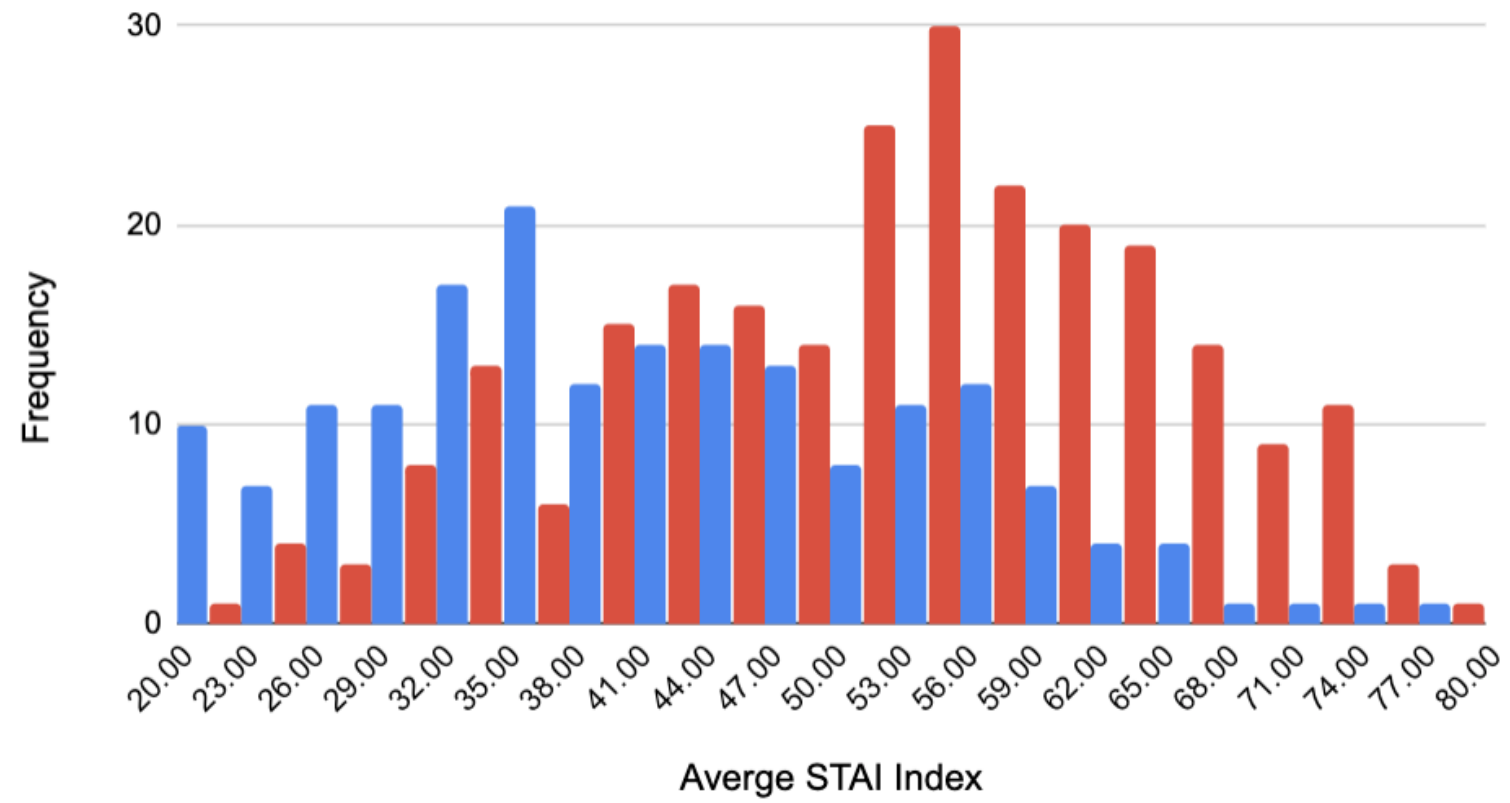

Figure 2. Average STAI index score among students (red bars) and adults (blue bars)

Students have a much greater frequency of higher scores reflecting higher reported anxiety within this cohort. The highest frequency of students' scores is 56; in comparison non-students report a much broader spread of scores closer to Normal distribution, with the highest frequency of non-students being 35 . 


\section{Analysis}

Table 1. Comparison of STAI index average scores between US and Ireland/Italy student and employed adult scores

\begin{tabular}{|c|c|c|c|}
\hline & $\begin{array}{c}\text { United States } \\
\text { Index Avg }\end{array}$ & $\begin{array}{c}\text { Ireland/Italy } \\
\text { Index Avg }\end{array}$ & Percent Difference: \\
\hline Students & $51.22(\mathrm{n}=82)$ & $52.34(\mathrm{n}=118)$ & $2.1 \%$ \\
\hline Employed Adults & $45.80(\mathrm{n}=63)$ & $41.55(\mathrm{n}=60)$ & $10.22 \%$ \\
\hline
\end{tabular}

There was no significant difference between the average STAI indices of students in UK/Ireland/Italy and students in the US in contrast to the OECD report in 2018 which found that European students tend to have greater anxiety towards their education.

Table 2: Comparison of STAI index average scores for students and employed adults with 2015 Normative data

\begin{tabular}{|c|c|c|c|}
\hline & $\mathbf{2 0 2 0}$ & 2015 Normative Data & Percent Change \\
\hline Students & $49.85(\mathrm{n}=237)$ & $38.81(\mathrm{n}=1279)$ & $28.45 \%$ \\
\hline Employed Adults & $42.45(\mathrm{n}=142)$ & $35.46(\mathrm{n}=1838)$ & $19.71 \%$ \\
\hline
\end{tabular}

In comparison with the 2015 normative data, the average STAI index for students has increased $28.45 \%$, a total of 11.04 points. When shown a list of possible reasons for their stress, $88 \%$ of these students reported one of the causes of stress was due to education management, and 38\% reported they had difficulty managing their workload and deadlines.

However, the comparison between the 2015 normative scores and this survey should be put into the context of generally increasing levels of stress among students. For example, according to the 2018 American College Health Association (ACHA, 2018) report 22\% of students have felt overwhelming anxiety in the last twelve months, and $27.6 \%$ of students have felt overwhelming anxiety in the last two weeks. This is significantly higher than the 2013 report, which noted that $19 \%$ of students felt overwhelming anxiety in the last 12 months, and $20.4 \%$ of students felt overwhelming anxiety in the last two weeks (ACHA, 2013). While it is not possible to separate the long term trend with the impact of COVID-19, the percentage increase found here is still significantly higher than the ACHA reported increase prior to COVID-19.

Compared to the 2015 Mindmap normative data, the average STAI index for adults has increased 19.71\%, a total of 6.99 points. When shown a list of possible sources of their stress, $67.42 \%$ of responders noted that their stress is due to Coronavirus fears, with $75 \%$ of the respondents being split between fear of a loved one contracting the virus and fear of prolonged social isolation. As is the case with students, it should be noted that there is evidence of an upward trend in workplace stress in particular prior to COVID-19. For example, a Korn Ferry Institute survey (2020) found that $2 / 3$ of respondents reported that the workplace is more stressful now than 5 years ago.

When respondents were categorized by age, respondents under 18 years old (representative of high school / secondary school students) received an average STAI index of 52.89, almost 15\% higher than the STAI Index of those aged 25-34. The age group with the second highest average STAI index was those aged 18-24 (representative of those in college and post-graduate studies) with an average STAI index of 50.25\%. Additionally, the average STAI index of those approximately aged 18-39 in this survey was 47.48, significantly greater than the normative data reporting the average index for this group as 36.54 . 


\section{Gender}

Table 3: Comparison of student STAI index average scores by self-reported gender with 2015 Normative data

\begin{tabular}{|c|c|c|c|c|c|c|}
\hline \multirow{2}{*}{} & \multicolumn{3}{|c|}{ 2015 Normative data } & \multicolumn{2}{c|}{$\mathbf{2 0 2 0}$} \\
\cline { 2 - 6 } & Male & Female & $\begin{array}{c}\text { Percent Dif- } \\
\text { ference }\end{array}$ & Male & Female & $\begin{array}{c}\text { Percent Dif- } \\
\text { ference }\end{array}$ \\
\hline Students & $\begin{array}{c}37.96 \\
(\mathrm{n}=526)\end{array}$ & $\begin{array}{c}39.65 \\
(\mathrm{n}=753)\end{array}$ & $4.26 \%$ & $46.48(\mathrm{n}=69)$ & $53.17(\mathrm{n}=166)$ & $12.58 \%$ \\
\hline
\end{tabular}

Those who reported their gender as "Female" reported a higher score of 53.17, a much greater score than "Males, with an average STAI index of 46.48. Research has previously shown that women report higher rates of feeling lonely / isolated (Henning-Smith, Ecklund et al, 2018).

Other research has shown that men are more often socially isolated than women (Vandervoort, 2000). One interpretation of these scores could be that men may be less impacted than women because they are more accustomed to social isolation and therefore on average their anxiety during mandatory isolation and quarantine could be lower than among women.

From 2015 to 2020, there was a $22.44 \%$ increase among male students. When asked which factors most contributed to their stress, $81.82 \%$ of male respondents noted that their stress was school-related, and $43.94 \%$ noted that their stress was coronavirus-related. $44.4 \%$ of those who reported coronavirus-related stress reported that they experienced difficulty managing their workload and deadlines, and $18.52 \%$ of this group reported that they experienced loneliness due to isolation. A further $60 \%$ of these respondents fear prolonged social isolation.

From 2015 to 2020 , there was a $34.10 \%$ increase among females. When asked which factors most contributed to their stress, over $90 \%$ of female respondents noted that their stress was school related, and $53 \%$ noted that their stress was coronavirus related. $35.86 \%$ of those who reported school related stress had difficulty managing their workload, with $20.69 \%$ reporting loneliness due to not interacting with people in school and $18.62 \%$ reporting disappointment over disruption of the school year. Furthermore, $54 \%$ of those who reported a source of their coronavirus stress was fear of prolonged social isolation, with $30 \%$ expressing fear of a loved one contracting the virus.

The greater increase among female students is striking but in line with findings using the Reynolds \& Richmond's Anxiety Scale (RCMAS) which suggested that female students experience higher anxiety in schools than males (Hosseini, Khazali, 2013).

The comparison between male and female student respondents shows that female students did report a statistically significant higher rate than male students.

\section{Household Size:}

Table 3: Comparison of STAI index average scores by self-reported gender with 2015 Normative data

\begin{tabular}{|c|c|c|c|}
\hline & $\mathbf{3 3}$ & $\mathbf{4 +}$ & Percent Change \\
\hline Students & $52.91(74)$ & $50.75(163)$ & $4.26 \%$ \\
\hline Adults & $40.64(60)$ & $44.67(69)$ & $9.02 \%$ \\
\hline
\end{tabular}

The hypothesis prior to analyzing the responses was that individuals in smaller households might be more severely impacted by social distancing than those with a larger household size and hence potentially greater social support. However, the analysis did not find any effect for students and a larger effect among adults. 


\section{Discussion}

Since the novel coronavirus was first reported in China, governments have aimed to cull its spread and raise awareness of the symptoms of the infection. On January 23rd, 2020, China implemented a mandatory quarantine of Wuhan; this resulted in all public transportation being suspended, airports closing, and public gathering being banned3. By late March, almost 250 million EU citizens were living under quarantine measures, and 32 US states implemented lockdown procedures. These measures are collectively known as social distancing and self-isolation.

Given the prior research reporting higher levels of stress and mental strain experienced by students during normal conditions, the consequences of social distancing and self-isolation could be expected to more significantly impact students in comparison with non-students. Similarly, research into gender and differences between the United States of America and Europe suggested that there should also be score differences between male and female students and between respondents residing in the United States of America and Europe. The final research hypothesis was that differences in household size would impact scores due to a connection between household size and available social support.Comparing the available scores from 2015 with the scores reported in this study, STAI scores reported by students did increase more than those reported by the employed adults ( $28.45 \%$ and $19.71 \%$ respectively). The cause of stress was clearly related to educational issues with $88 \%$ of students reporting stress identifying one of the causes of stress was education management, and a further $38 \%$ reported they had difficulty managing their workload and deadlines. The level of reported STAI was highest among those under 18 years old.

Female students reported significantly higher STAI scores than male students $(+12.58 \%)$ with the top three reasons identified as school related stress $(90 \%)$, coronavirus related $(53 \%)$ and stress related to difficulty managing their workload (35.86\%).

The introduction and duration of the Social distancing and self-isolation measures varied between the United States of America and Europe. However, this study found that there were no differences between the European and US student scores reported.

The final hypothesis that stress would be inversely related to household size with larger households providing better supports was not supported by this study. However, this may reflect the size of the effect or other confounding factors which could not be controlled for.

\section{Conclusion}

The results of this study suggest that the COVID-19 related Social Distancing and Self-isolation lead to a greater increase in stress among students than among adults as measured by STAI index. The stress was highest among high school age students and among female students. The causes of this stress are primary related to the impact on education of the measures rather than directly related to the pandemic.

\section{Limitations}

The process of recruiting participants through Instagram and Facebook may reduce the representativity of the adult sample compared to using a representative panel. The results were not reweighted to represent the entire population.

\section{Acknowledgements}

I would like to thank Luke Reaper of Behaviors and Attitudes Ltd, Ireland for his guidance on research methods. I would also like to thank The JED Foundation on their distribution of my survey and their support of my research. 


\section{References}

Anxiety and Depression Association of America (2015), National College Health Assessment, Retrieved from https://adaa.org/finding-help/helping-others/college-students/facts

Spielberger, C. D., Gorsuch, R. L., Lushene, R., Vagg, P. R., \& Jacobs, G. A. (1983). Manual for the State-Trait Anxiety Inventory. Palo Alto, CA: Consulting Psychologists Press.

Newport Academy (2020), The Effects of Social Isolation on Mental Health. Retrieved from https://www.newportacademy.com/resources/mental-health/effects-of-social-isolation-on-mental-health/

Organization for Economic Cooperation and Development (2018), The OECD Programme for International Student Assessment (PISA) 2015. Retreived from https://www.oecd.org/pisa/pisa-2015-results-in-focus.pdf

American College Health Association (2018), SPRING 2018 Reference Group Executive Summary. Retrieved from https://www.acha.org/documents/ncha/NCHA-II Spring 2018 Reference Group Executive Summary.pdf

American College Health Association (2013), SPRING 2018 Reference Group Executive Summary. Retrieved from https://www.acha.org/documents/ncha/ACHA-NCHA-II ReferenceGroup ExecutiveSummary Spring2013.pdf

Korn Ferry Institute, (2020), Workplace Stress Continues to Mount. Retrieved from https://www.kornferry.com/insights/articles/workplace-stress-motivation

Henning-Smith, C., Ecklund, A., Moscovice, I., Kozhimanni K., (2018), Gender Differences in Social Isolation and Social Support among Rural Residents, Policy Brief, August 2018, University of Minnesota Rural Health Research Center http://rhrc.umn.edu/wp-content/files mf/1532458325UMNpolicybriefsocialisolationgenderdifferences.pdf

Vandervoort D.,(2000). Social isolation and gender, Current Psychology, 19. Retrieved from: https://link.springer.com/article/10.1007/s12144-000-1017-5

Hosseini, L., Hkazali H., (2013), Comparing the Level of Anxiety in Male \& Female School Students, Procedia Social and Behavioral Sciences, 84. Retrieved from: https://www.sciencedirect.com/science/article/pii/S1877042813015735 